\title{
Impact of Deep Soil Layer on Terrestrial Microwave Emission for a Bare Agricultural Field
}

\author{
Cihan DOGUSGEN (ERBAS) \\ Dept. of Electrical and Electronics Engineering, Istanbul Yeni Yuzyil University, \\ Yilanli Ayazma Street 26, 34010 Istanbul, Turkey \\ cihan.dogusgen@yeniyuzyil.edu.tr
}

Submitted July 20, 2016 / Accepted March 27, 2017

\begin{abstract}
In this study, we investigated the deep (semiinfinite) soil contribution to the brightness temperature at $1.4 \mathrm{GHz}$ calculated through a modified incoherent radiative transfer model. We reproduced the measured brightness temperature collected by a dual L-band radiometer in a bare agricultural field. We found that exclusion of a semi-infinite soil layer in the incoherent model significantly decreased the brightness temperature when the measurement depth in the model was closer to the emitting depth, which is the first few centimeters from the top of soil. The maximum brightness temperature differences between the cases with and without the semi-infinite layer in the incoherent model were computed to be $6.8444 \mathrm{~K}$, $2.8891 \mathrm{~K}, 0.2477 \mathrm{~K}$ and $0.0004 \mathrm{~K}$ for the measurement depths of $4 \mathrm{~cm}, 5 \mathrm{~cm}, 8 \mathrm{~cm}$ and $16 \mathrm{~cm}$, respectively. Based on a comparison with another coherent radiative transfer model, we observed that inclusion of the deep soil layer significantly improved the precision of the incoherent model regardless of the measurement depth. Our results could be one example of improving the accuracy of radiative transfer models, which might be applied to other radiative transfer models and increase the precision of soil moisture retrieval calculations.
\end{abstract}

\section{Keywords}

Radiative transfer model, soil moisture, bare soil, incoherent model, brightness temperature, microwave radiometry

\section{Introduction}

Soil moisture is a reservoir of the water cycle that impacts precipitation patterns [1], droughts and floods [2], physical, chemical and biological processes that occur within the soil [3], agricultural productivity [4], weather forecasting and seasonal climate prediction [5] by controlling the energy and moisture exchange between the atmosphere and land surface. Microwave radiometry is an effective way for soil moisture retrieval. The appropriate wavelength for soil moisture measurements falls in L-band (1 to
$2 \mathrm{GHz})$ at a wavelength of $21 \mathrm{~cm}(1.4 \mathrm{GHz})$ operating at near-nadir look angles and horizontal polarization [6], [7]. The $21 \mathrm{~cm}$ wavelength allows significant penetration through vegetation and decreases the normalized surface roughness [8]. Global measurements of soil moisture first started in 2009 with ESA's Soil Moisture and Ocean Salinity - SMOS mission [9]. The Soil Moisture Active Passive - SMAP mission of NASA followed in 2015 [10].

Radiative transfer theory originates from the law of energy conservation [11]. This method has long been used to explain scattering, emission and absorption of the microwave radiation within a defined media [12]. It allows us to quantitatively interpret the impacts such as soil properties, vegetation, and soil surface roughness on the emitted radiation of the soil. Various methods have been developed in order to model the brightness temperature [13-16], which is a measure of radiated power.

In this article, we provided a modification to a previously developed incoherent radiative transfer model to include the deep soil layer contribution to the modeled brightness temperature. We hypothesized that deep soil layer affected the emission characteristics (and therefore emissivity) of the soil, and the amount of that impact depended on where the measurement depth, which is the deepest point through the soil where the dielectric constant can be defined, was chosen. To verify our hypothesis, we started with a fictitious air - dry soil - wet soil system and computed the resulting incoherent emissivity profile for the cases with and without the deep soil layer. Then we applied the two versions of the incoherent model to a dataset collected in Michigan, USA to see the significance of the difference in brightness temperature in Kelvins.

We organized our article as follows: In Sec. 2, we described materials and methods including the field measurements along with their analysis. Furthermore, we explained the radiative transfer models (original and the modified incoherent models as well as the coherent model) and auxiliary models (ALEX model, dielectric mixing model and soil surface roughness model). In Sec. 3, we presented our results and assessments related to the reproduction of measured brightness temperature, and analysis of deep soil layer impact. In Sec. 4 we provided our conclusion. 


\section{Material and Methods}

\subsection{Measurements}

The data used in this study comes from Hornbuckle et al. [17] and Dogusgen \& Hornbuckle [18]. The experimental field was located in southeastern Michigan, USA, and was planted in maize. Dimensions of the site was $800 \mathrm{~m}(\mathrm{E}-\mathrm{W})$ and $400 \mathrm{~m}(\mathrm{~N}-\mathrm{S})$ Soil texture consisted of $16.1 \%$ sand, $55 \%$ silt, $28.9 \%$ clay ( silty clay loam). Rows were planted E-W with an average spacing of $0.77 \mathrm{~m}$. Figure 1 shows a photograph of the experimental site.

We collected measurements of volumetric soil moisture content at $1.5 \mathrm{~cm}$ and $4.5 \mathrm{~cm}$ through the soil representing the $0-3 \mathrm{~cm}$ and $3-6 \mathrm{~cm}$ average water content, respectively. We measured the soil temperature in a similar approach. A micrometeorological station collected several micrometeorological parameters such as precipitation, wind speed, relative humidity, air temperature and downwelling solar/atmospheric radiation. A truck-mounted, direct sampling digital radiometer [19] measured the h-pol brightness temperature of a part of the field that was not planted. The radiometer was deployed at the height of $10 \mathrm{~m}$ with an incidence angle of $35^{\circ}$ and a footprint of approximately $40 \mathrm{~m}^{2}$. It operated at $1.4 \mathrm{GHz}$, and collected measurements every 2 minutes with a precision of $0.4-0.5 \mathrm{~K}$. Half power beamwidth levels ( $\mathrm{E}$ and $\mathrm{H}$ plane) of the radiometer antenna were $-21^{\circ}$. Side lobe levels were $-20 \mathrm{~dB}$.

\subsection{Data Analysis}

We were interested in the short-term (15 hours) variations of brightness temperature. In order to understand the effects that influence the brightness temperature change within the time period of interest, how the soil moisture and soil temperature varied should be considered. Figure 2 illustrates the variations of $0-3 \mathrm{~cm}$ average soil moisture, soil temperature at $1.5 \mathrm{~cm}$ from the top of soil, and measured brightness temperature. As expected, the brightness temperature decreases in an almost linear fashion with the increasing soil moisture content. The soil temperature has a decreasing trend as well. We modeled the soil moisture and soil temperature profiles through a land-surface model:

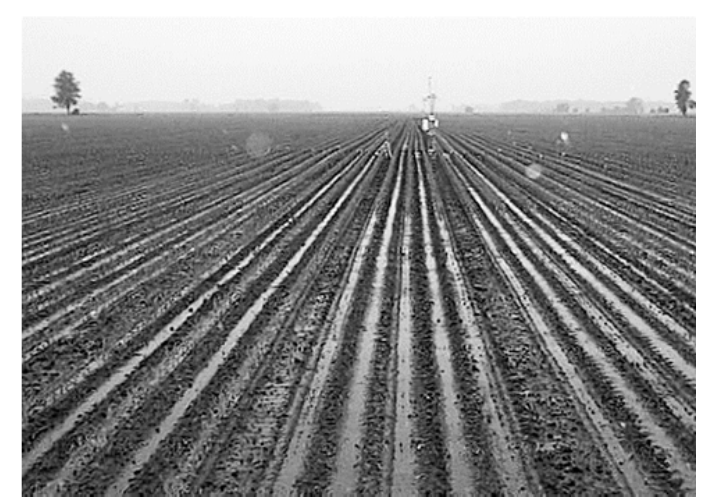

Fig. 1. Picture of the experimental area. The photograph was taken after a rain event on day of year 145 .
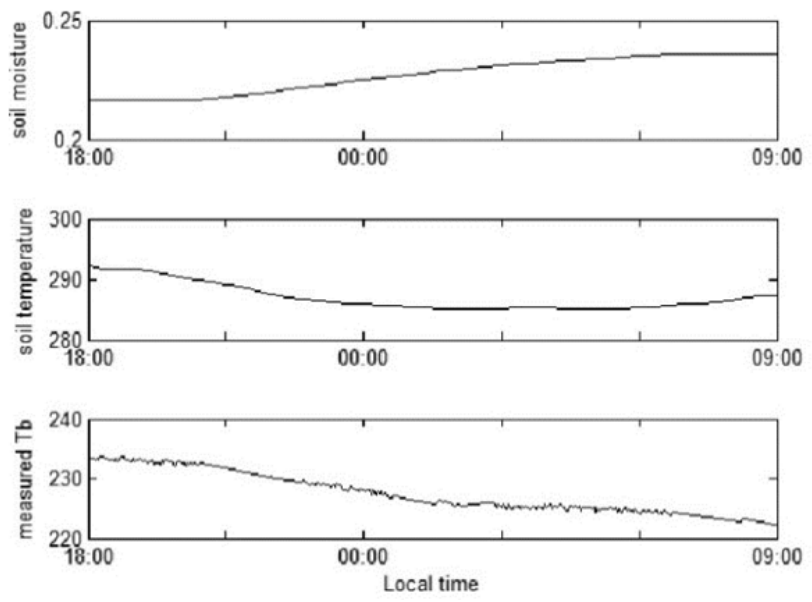

Fig. 2. Zero to $3 \mathrm{~cm}$ average soil moisture (top), soil temperature at $1.5 \mathrm{~cm}$ from the top of soil (middle), and measured brightness temperature (bottom) on days of year 143 and 144. No precipitation was recorded during the time of interest.

Atmospheric and Land-Surface Exchange Model (ALEX) [20]. More information on ALEX is given in Sec. 2.3.3. The reason we used a model such as ALEX is due to the difficulty of sampling at all depths in field experiments, whereas ALEX can compute the soil moisture and soil temperature values of all soil layers. Hence, by using ALEX, the precision of the radiative transfer model of interest was significantly improved. Furthermore, the agreement between the measured and modeled soil moisture/soil temperature of interest was verified in a previous study [21].

\subsection{Modeling}

We reproduced the measured brightness temperature through an incoherent radiative transfer model that we modified to add the deep soil contribution to soil emissions. Original version of the model was developed by Burke et al. [22]. Initially, we also used a coherent radiative transfer model to verify that the incoherent model is capable of reproducing the measured brightness temperature. After the verification step, we quantified the amount of emissions generated by the deep soil layer through comparison computations (with and without the deep soil layer) and plots. Furthermore, we explored the effect of depth at which the deep soil layer starts.

Other than the radiative transfer models, we utilized the ALEX model, a soil surface roughness model, and a dielectric mixing model throughout the study. We used ALEX to generate the two inputs of the radiative transfer models: Volumetric soil moisture and the soil temperature profiles. Soil surface roughness model generated an amount of extra emissions, added to the emissions of the specular surface, because of the rough nature of the soil. The dielectric mixing model produced the soil dielectric constant profile, another input for the radiative transfer models. The soil surface roughness model and the dielectric mixing model were embedded in the radiative transfer model programming codes while ALEX was run as a separate model. 
Descriptions of the above mentioned models are given in Sec. 2.3.1, 2.3.2 and 2.3.3.

\subsubsection{Incoherent Model and the Re-derived Version (Inclusion of Semi-Infinite Layer)}

The incoherent model assumes that the radiation is incoherent (in which the phase effect is avoided), soil moisture and soil temperature are functions of depth only, and soil dielectric and thermal properties are constant across layers of finite thickness.

The system geometry for a one-layer system is illustrated in Fig. 3. The observation angle and thickness of the layer are denoted as $\theta$ and $\Delta z_{1}$, respectively. The depth varies across $z$ direction.

Radiation emitted from the one-layer system represented by $T_{\mathrm{B}}$ is

$$
T_{\mathrm{B}}\left(1^{+}, \theta\right)=T_{1}\left(1+\frac{R_{2}}{L_{1}}\right)\left(1-R_{1}\right)
$$

where $T_{1}$ and $R_{i}, i=1,2$ are the soil temperature of layer 1 , and the reflectivities for boundary 1 and boundary 2, respectively, and

$$
L_{1}=\exp \left(2 \alpha_{1} \Delta z_{1} / \mu\right)
$$

is the power loss factor, where $\mu_{1}$ is the direction cosine for layer 1 , and $\alpha_{1}$ is the attenuation constant of layer 1 , which is defined as

$$
\alpha_{1}=\left(\frac{2 \pi}{\lambda_{0}}\right)\left|\operatorname{Im}\left(\sqrt{\varepsilon_{\mathrm{r} 1}}\right)\right|
$$

where $\lambda_{0}$ and $\varepsilon_{\mathrm{r} 1}$ are the free-space wavelength and relative dielectric constant of layer 1 , respectively. $T_{\mathrm{B}}\left(1^{+}, \theta\right)$ denotes the brightness temperature above the first boundary between air and soil at an observation angle of $\theta$. is [20]

Radiation emitted from the soil for an $N$-layer system

$$
\begin{aligned}
T_{\mathrm{B}}\left(1^{+}, \theta\right)= & T_{1}\left(1+\frac{R_{2}}{L_{1}}\right)\left(1-R_{1}\right)+ \\
& T_{2}\left(1+\frac{R_{3}}{L_{2}}\right)\left(\frac{\left(1-R_{1}\right)\left(1-R_{2}\right)}{L_{1}}\right)+\ldots+ \\
& T_{N}\left(1+\frac{R_{N+1}}{L_{N}}\right)\left(\frac{\left(1-R_{1}\right)\left(1-R_{2}\right) \ldots\left(1-R_{N}\right)}{L_{1} L_{1} \ldots L_{N-1}}\right) .
\end{aligned}
$$

For an $\mathrm{N}$-layer system, we re-derived (4) to take into account the deep soil contribution to the total soil emissions. The re-derivation process is given in (5)-(18). It is clear that we have an extra last term in our resulting expression (18) that is missing in (4) due to our boundary condition given by (11). We called that extra term as the semi-infinite layer effect or deep soil effect, because it is the semi-infinite region below the $N^{\text {th }}$ layer that causes the extra emission term in (18). We denoted that semi-infinite

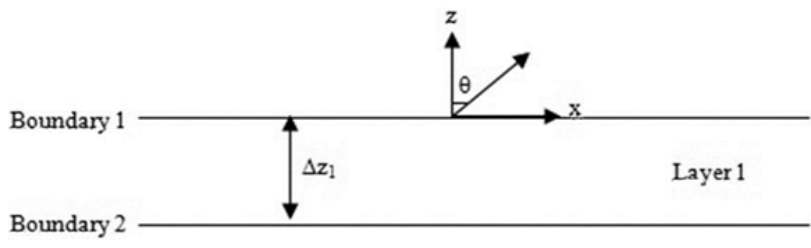

Fig. 3. Soil layer, boundaries of the layer, layer thickness, and the incidence angle for a one-layer system.

region as $(N+1)^{\text {st }}$ layer in $(18)$, in which layer depth is not a necessary variable to compute the last term. Steps of our re-derivation are as follows:

The total energy received at the bottom of a boundary $i$ due to emission by all strata in layer $i$ can be expressed as

$$
T_{\mathrm{s}}(i)=T_{i}\left(1-\frac{1}{L_{i}}\right)
$$

where $T_{i}$ and $L_{i}$ are the physical temperature and power loss factor of layer $i$. For a two-layer system, the geometry is shown in Fig. 4. Using that geometry, we obtain

$$
T_{\mathrm{S}}\left(1^{+}\right)=\left\lfloor T_{\mathrm{S}}\left(1^{-}\right)\right\rfloor\left(1-R_{1}\right) .
$$

In (6), superscripts ${ }^{+}$and ${ }^{-}$correspond the upper and lower parts of boundary 1, respectively. We utilized the same logic in the following re-derivation process.

$$
\begin{gathered}
T_{\mathrm{s}}\left(1^{-}\right)=T_{\mathrm{s}}(1)+\frac{T_{\mathrm{s}}\left(2^{+}\right)}{L_{1}}, \\
T_{\mathrm{s}}\left(2^{+}\right)=\left[T_{\mathrm{s}}\left(2^{-}\right)\right]\left(1-R_{2}\right)+R_{2} T_{\mathrm{s}}(1), \\
T_{\mathrm{s}}\left(2^{-}\right)=\left[\frac{T_{\mathrm{s}}\left(3^{+}\right)}{L_{2}}+T_{\mathrm{s}}(2)\right], \\
T_{\mathrm{s}}\left(3^{+}\right)=\left[T_{\mathrm{s}}\left(3^{-}\right)\right]\left(1-R_{3}\right)+R_{3} T_{\mathrm{s}}(2), \\
T_{\mathrm{s}}\left(3^{-}\right)=T_{\text {physical }}(3) .
\end{gathered}
$$

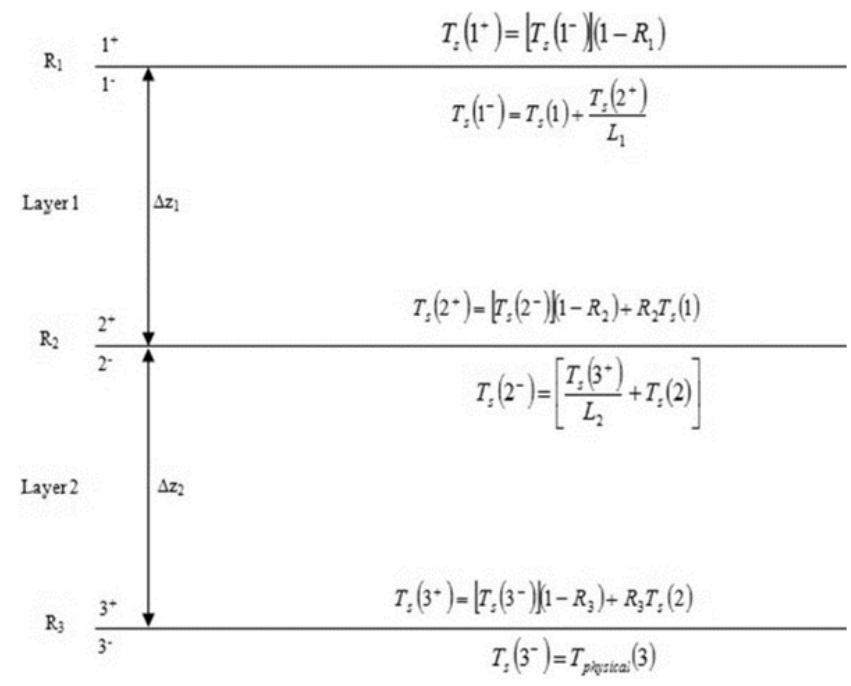

Fig. 4. A two-layer system geometry. 
Using (11) in (10)

$$
\left(\frac{T_{\text {physical }}(3)\left(1-R_{3}\right)+R_{3} T_{\mathrm{s}}(2)}{L_{2}}+T_{\mathrm{s}}(2)\right)\left(1-R_{2}\right)+R_{2} T_{\mathrm{s}}(1) \text {. }
$$

Using (12) in (9)

$$
T_{\mathrm{s}}\left(2^{-}\right)=\frac{T_{\text {physical }}(3)\left(1-R_{3}\right)+R_{3} T_{\mathrm{s}}(2)}{L_{2}}+T_{\mathrm{s}}(2) .
$$

Using (13) in (8)

$$
\left(\frac{T_{\text {physical }}(3)\left(1-R_{3}\right)+R_{3} T_{\mathrm{s}}(2)}{L_{2}}+T_{\mathrm{s}}(2)\right)\left(1-R_{2}\right)+R_{2} T_{\mathrm{s}}(1) \text {. }
$$

Using (14) in (7)

$$
\begin{aligned}
T_{\mathrm{s}}\left(1^{-}\right)= & T_{\mathrm{s}}(1)+ \\
& \frac{\left(1-R_{2}\right)}{L_{1}}\left(\frac{T_{\text {physical }}(3)\left(1-R_{3}\right)+R_{3} T_{\mathrm{s}}(2)}{L_{2}}\right)+ \\
& \frac{\left(1-R_{2}\right) T_{\mathrm{s}}(2)}{L_{1}}+\frac{R_{2} T_{\mathrm{S}}(1)}{L_{1}} .
\end{aligned}
$$

Using (15) in (6)

$$
\begin{aligned}
& T_{\mathrm{s}}\left(1^{+}\right)=\left(1-R_{1}\right) \\
& {\left[\begin{array}{l}
T_{\mathrm{s}}(1)+ \\
\frac{1}{L_{1}}\left[\left(\frac{T_{\text {physical }}(3)\left(1-R_{3}\right)+R_{3} T_{\mathrm{s}}(2)}{L_{2}}+T_{\mathrm{s}}(2)\right)\left(1-R_{2}\right)+\right] \\
R_{2} T_{\mathrm{s}}(1)
\end{array}\right] .}
\end{aligned}
$$

Rearranging (16)

$$
\begin{aligned}
T_{\mathrm{s}}\left(1^{+}\right)= & T_{\mathrm{s}}(1)\left(1+\frac{R_{2}}{L_{1}}\right)\left(1-R_{1}\right)+ \\
& T_{\mathrm{s}}(2)\left(1+\frac{R_{3}}{L_{2}}\right)\left(\frac{\left(1-R_{1}\right)\left(1-R_{2}\right)}{L_{1}}\right)+ \\
& T_{\text {physical }}(3)\left(\frac{\left(1-R_{1}\right)\left(1-R_{2}\right)\left(1-R_{3}\right)}{L_{1} L_{2}}\right) .
\end{aligned}
$$

For an $N$-layer system

$$
\begin{aligned}
T_{\mathrm{B}}\left(1^{+}, \theta\right)= & T_{\mathrm{S}}(1)\left(1+\frac{R_{2}}{L_{1}}\right)\left(1-R_{1}\right)+ \\
& T_{\mathrm{s}}(2)\left(1+\frac{R_{3}}{L_{2}}\right)\left(\frac{\left(1-R_{1}\right)\left(1-R_{2}\right)}{L_{1}}\right)+ \\
& \ldots+ \\
& T_{\mathrm{s}}(N)\left(1+\frac{R_{N+1}}{L_{N}}\right)\left(\frac{\left(1-R_{1}\right)\left(1-R_{2}\right) \ldots\left(1-R_{N}\right)}{L_{1} L_{2} L_{3} \ldots L_{N-1}}\right)+ \\
& T_{\mathrm{s}}(N+1)\left(\frac{\left(1-R_{1}\right)\left(1-R_{2}\right) \ldots\left(1-R_{N}\right)\left(1-R_{N+1}\right)}{L_{1} L_{2} L_{3} \ldots L_{N-1} L_{N}}\right) .
\end{aligned}
$$

The last term in (18) corresponds to the deep soil layer contribution.

\subsubsection{Coherent Model}

Njoku and Kong's [23] coherent radiative transfer model assumes that soil is a layered and a horizontallyhomogeneous medium in which soil moisture and soil temperature are functions of vertical direction ( $z$-axis).

As the model takes the amplitude and phase of the reflections between the layers into consideration, it is regarded as a coherent technique.

Horizontally-polarized (h-pol) brightness temperature $T_{\mathrm{Bh}}$ is given by (19):

$$
T_{\mathrm{Bh}}(\theta)=\frac{k}{\cos \theta} \int_{-\infty}^{0} \mathrm{~d} z T(z) \varepsilon_{\mathrm{r}}^{\prime \prime}(z)|\Psi(z)|^{2}
$$

where $\varepsilon_{\mathrm{r}}(z)=\varepsilon_{\mathrm{r}}(z)+\varepsilon_{\mathrm{r}}{ }^{\prime \prime}(z)$ and $k$ are the relative dielectric constant, and free-space wave number, respectively. $T(z)$ corresponds to the vertical soil temperature profile, and $k_{\mathrm{x}}=k \sin \theta$. The function $\Psi(z)$ is governed by $(20)$ :

$$
\frac{\mathrm{d}^{2} \Psi(z)}{\mathrm{d} z^{2}}+\left[\varepsilon_{\mathrm{r}}(z) k^{2}-k_{\mathrm{x}}^{2}\right] \Psi(z)=0 .
$$

We used the coherent model as a reference model whose reliability was also verified by another study [24].

\subsubsection{Auxiliary Models}

We used three auxiliary models in conjunction with the radiative transfer models: A land surface model (ALEX), a dielectric mixing model, and a soil surface roughness model:

ALEX explains energy and carbon exchange in a soilplant-atmosphere system with minimal empirical relationships. Moreover, application to various types of crops is possible. ALEX utilizes the Richard' s equation, and factors such as soil surface water, saturated conductivity and soil water potential to compute the soil moisture profile against time. The soil is divided into layers whose depths are specified by the user. Layer depths do not need to be uniform. An input file includes several land and atmosphere parameters (excluding vegetation parameters as we dealt with bare soil) such as soil bulk density, soil texture, water vapor pressure, precipitation, wind speed, and thermal radiation from sky. By running ALEX, we generated the time-dependent soil moisture profile along with the soil temperature profile. Next, we input those profiles into the radiative transfer models.

The dielectric mixing model [25] evaluates the microwave dielectric behavior of soil-water mixtures. This model assumes that the soil-water mixture consists of four components: dry soil, air, free and bound water. The resulting relative dielectric constant is

$$
\varepsilon=\left(\sum_{i} V_{i} \varepsilon_{i}^{\tau}\right)^{1 / \tau}
$$


where $\tau$ is a constant shape factor, $V_{i}$ and $\varepsilon_{i}$ are the volume ratio and the relative dielectric constant of each component, respectively.

Choudhury et al. [26] developed a soil surface roughness model that is based on standard deviation of surface height $\sigma$. If the scattering surface is statistically rough such that there is no correlation between the amplitudes of the waves scattered by two points on the surface, and the surface height distribution is represented by a Gaussian distribution with a zero mean and a standard deviation $\sigma$, then a roughness parameter $h$ can be defined

$$
h=4 o^{2}\left(\frac{2 \pi}{\lambda_{0}}\right)^{2} .
$$

Assuming that the specular surface reflectivity $R_{\text {specular }}$ is known

$$
R_{\text {rough }}(\theta)=R_{\text {specular }}(\theta) \exp \left(-h \cos ^{2} \theta\right)
$$

where $R_{\text {rough }}$ is rough surface reflectivity. Then the rough surface emissivity $E_{\text {rough }}$ is

$$
E_{\text {rough }}(\theta)=1-R_{\text {rough }}(\theta) \text {. }
$$

\section{Results and Discussion}

To understand the impact of deep soil layer on incoherent emissivity, we first considered a testcase geometry given in Fig. 5. The geometry was a one-layer system $(N=1)$ of dry soil characterized by the relative permittivity of $\varepsilon_{\mathrm{r}}=4-\mathrm{j} 0.3$. The deep soil layer was represented by wet soil with a relative permittivity of $\varepsilon_{\mathrm{r}}=25-\mathrm{j} 5$. Soil temperature profile was uniform. Incidence angle was $35^{\circ}$ (consistent with our field measurements).

Figure 6 compares the h-pol emissivities computed with the incoherent model for the configuration in Fig. 5 with and without the semi-infinite layer. We plotted both emissivity variations against dry soil depth. Maximum depth of the dry soil layer was $20 \mathrm{~cm}$. From Fig. 6, it is clear that the emissivity values significantly became larger when the semi-infinite layer was taken into account, which would also yield an increase in the brightness temperature. Note that when the dry soil depth was zero, the incoherent emissivity for the configuration without the semi-infinite layer effect was also zero. That was because all the emissivity was supposed to contribute from the semi-infinite layer, however there was no dry soil as the dry soil depth was zero. Since the semi-infinite layer was excluded in that plot, the resulting emissivity was therefore zero. The maximum difference (between the configurations with and without the semi-infinite layer) in emissivity was 0.6704 , occuring when the dry soil depth was zero.

Next, we explored how the deep soil layer affected the brightness temperature for the experimental data. To do that, we utilized the coherent model as a reference tool in order to verify the degree of agreement with the incoherent model for various cases. Figure 7 illustrates the first case

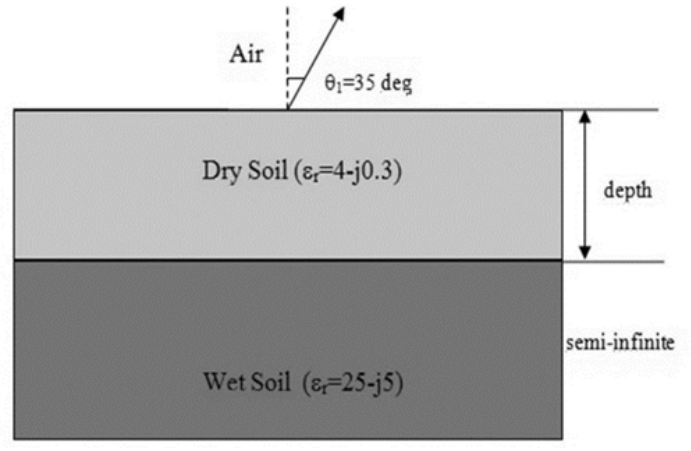

Fig. 5. Testcase geometry (air - dry soil - wet soil).

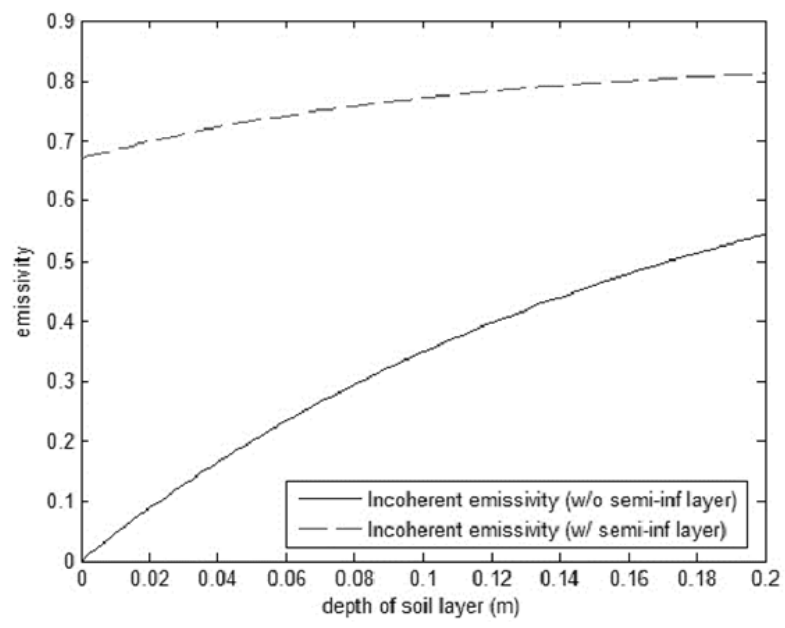

Fig. 6. Incoherent emissivity versus dry soil depth for the testcase geometry: Impact of the semi-infinite layer.

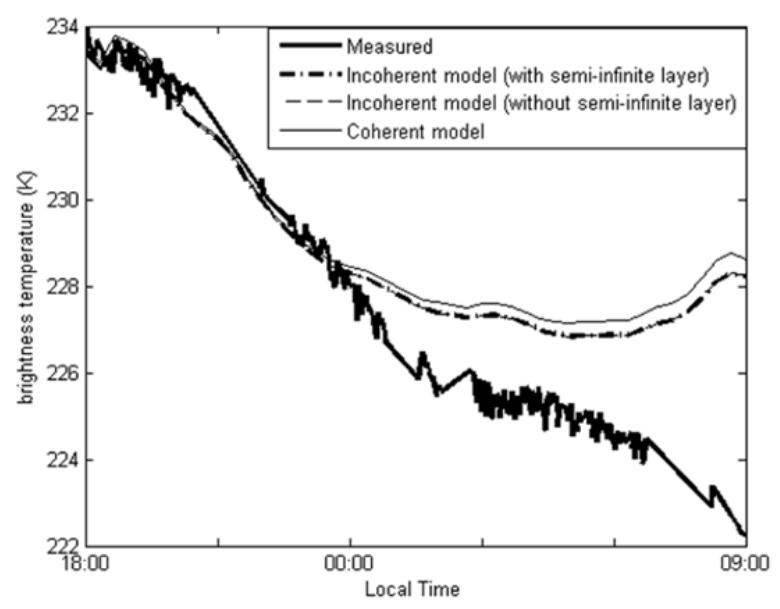

Fig. 7. Agreement between the incoherent and coherent models along with the impact of the semi-infinite layer on the incoherent model. Measurement depth is $16 \mathrm{~cm}$.

(Case 1): We observed a close agreement between the coherent and the incoherent models for a measurement depth of $16 \mathrm{~cm}$. Furthermore, Figure 7 depicts that the impact of semi-infinite soil layer on the brightness temperature produced by the incoherent model was negligible for that measurement depth. In that figure, the plots for the cases with and without the semi-infinite layer are indistinguishable as the maximum brightness temperature difference between those cases was only $0.0004 \mathrm{~K}$. Note that all 
results were generated for the h-pol with an incidence angle of $35^{\circ}$. Standard deviation of surface height was taken as $1.5 \mathrm{~cm}$ throughout the computations.

Then we considered another case (Case 2) for the measurement depth of $8 \mathrm{~cm}$, as given in Fig. 8. Maximum brightness temperature difference between the configurations with and without the semi-infinite layer for the incoherent model was $0.25 \mathrm{~K}$.

In Case 3 and Case 4, we carried out the same analysis for the measurement depths of $5 \mathrm{~cm}$ and $4 \mathrm{~cm}$, respectively. Maximum differences in the brightness temperature with and without the deep soil layer were $2.89 \mathrm{~K}$ and $6.84 \mathrm{~K}$, for Case 3 and Case 4, respectively. Figure 9 and Figure 10 show the associated plots. We utilized the coherent model plot of Case 1 as a reference for all cases.

In all four cases, it is obvious that the inclusion of the semi-infinite soil layer in the incoherent model adds extra amounts of brightness temperature, which is also consistent with the testcase. Also, the more the measurement depth decreased and reached/exceeded the emitting depth towards the top soil, the more the incoherent model without the semi-infinite layer could not reproduce the measured brightness temperature, which showed that modeling errors might occur due to the semi-infinite layer effect when it was not possible to collect samples of soil moisture as well as soil temperature. The measurement depth became a less important factor when the semi-infinite layer was taken into account. That was visible in Fig. 5 through Fig. 8 as the incoherent model with the semi-infinite layer closely followed the coherent model, which actually showed that inclusion of a semi-infinite soil layer returned more precise results even when it was not possible to sample (soil moisture and soil temperature) deep through the soil. Note that we obtained the semi-infinite soil layer effect on the brightness temperature by applying the boundary condition in (11), and eliminating the dependency of the last term in (18) from the variables $R$ and $L$ that require the knowledge of two neighbor layer characteristics and depths.

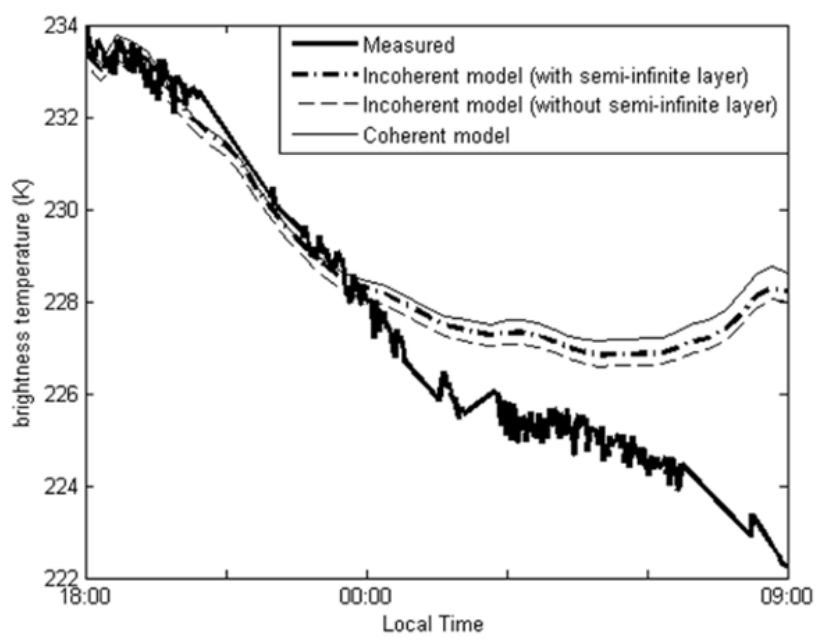

Fig. 8. Incoherent model result with and without the semiinfinite soil layer along with the coherent result as a reference. Measurement depth is $8 \mathrm{~cm}$.

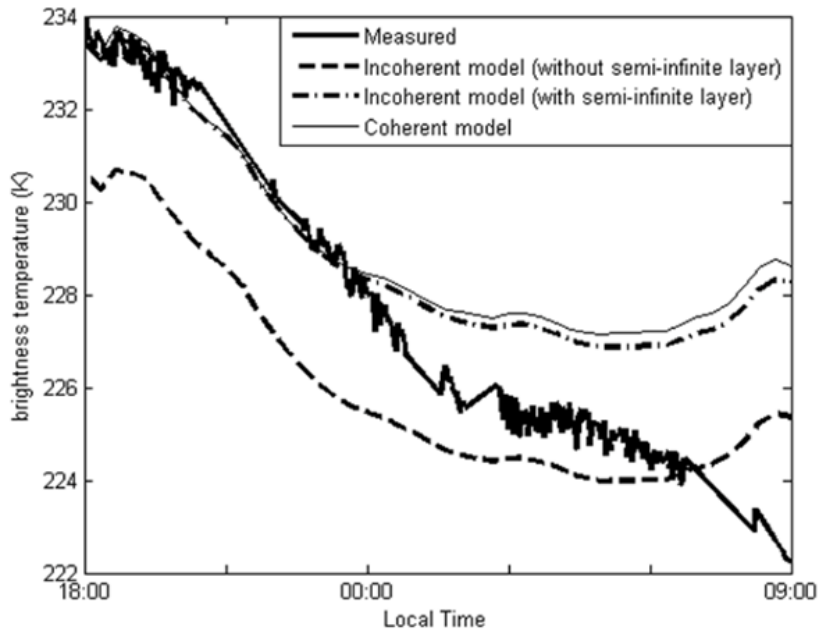

Fig. 9. Incoherent model result with and without the semiinfinite soil layer along with the coherent result as a reference. Measurement depth is $5 \mathrm{~cm}$.

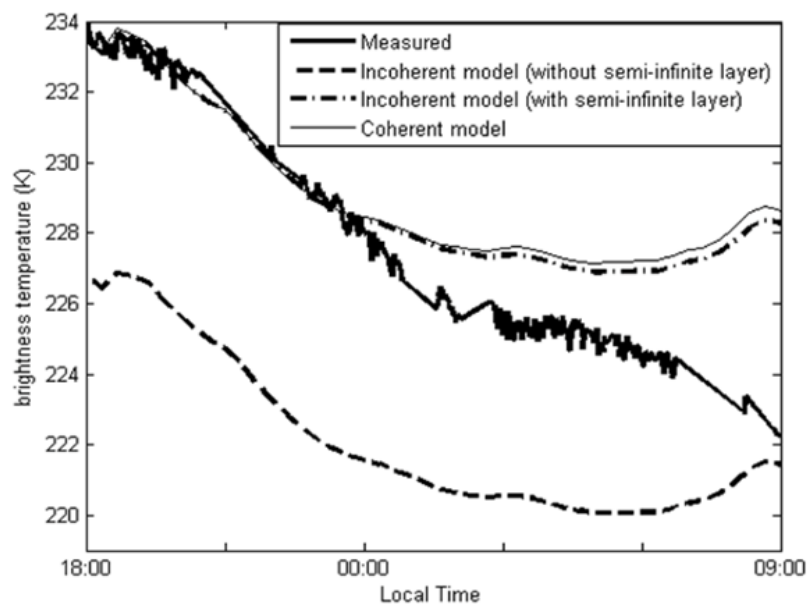

Fig. 10. Incoherent model result with and without the semiinfinite soil layer along with the coherent result as a reference. Measurement depth is $4 \mathrm{~cm}$.

\section{Conclusion}

We observed strong contributions to the incoherent model brightness temperature of bare soil at $1.4 \mathrm{GHz}$ due to the deep soil layer. Neglection of the semi-infinite soil layer returned significantly lower brightness temperatures. Largest differences occurred at a measurement depth of $4 \mathrm{~cm}$. Independent of the measurement depth, inclusion of the deep soil layer yielded agreement with the coherent model that was used as a reference model. We also tested how the deep soil layer affected the emissivity of a hypothetical air-dry soil-wet soil configuration. We obtained significantly larger emissivity values when the deep soil layer was taken into account. Our results let us better understand/interpret one of the different effects on measured brightness temperature that might be adapted to improve other possible radiative transfer models used in soil moisture inversion. Furthermore, consideration of the deep soil effect in modeling could compensate for the limited availability of soil moisture and soil temperature data in terms of model precision. 


\section{References}

[1] KOSTER, R. D., SUAREZ, M. J., HIGGINS, R. W., VAN DEN DOOL, H. M. Observational evidence that soil moisture variations affect precipitation. Geophysical Research Letters, 2003, vol. 30, no. 5. DOI: 10.1029/2002GL016571

[2] LAKSHMI, V., PIECHOTA, T., NARAYAN, U., et al. Soil moisture as an indicator of weather extremes, Geophysical Research Letters, 2004, vol. 31. DOI: 10.1029/2004GL019930

[3] AlvalA, R. C. S., GIElOW, R., DA ROCHA, H. R., et al. Intradiurnal and seasonal variability of soil temperature, heat flux, soil moisture content, and thermal properties under forest and pasture in Rondonia. Journal of Geophysical Research, 2002, vol. 107, no. D20, p. 1-20. DOI: 10.1029/2001JD000599

[4] KURUM, M. Quantifying scattering albedo in microwave emission of vegetated terrain. Remote Sensing of Environment, 2012, vol. 129, no. 2013, p. 66-74. DOI: 10.1016/j.rse.2012.10.021

[5] PRIGENT, C., AIRES, F., ROSSOW, W. B., et al. Sensitivity of satellite microwave and infrared observations to soil moisture at a global scale: relationship of satellite observations to in situ soil moisture measurements. Journal of Geophysical Research, 2005, vol. 110, no. D07110. DOI: 10.1029/2004JD005087

[6] SHI, J., CHEN, K. S., LI, Q., et al. A parametrized surface reflectivity model and estimation of bare-surface soil moisture with L-band radiometer. IEEE Transactions on Geoscience and Remote Sensing, 2002, vol. 40, no. 12, p. 2674-2686. DOI: 10.1109/TGRS.2002.807003

[7] DE ROO, R. D., ENGLAND, A. W., MUNN, J. Circular polarization for L-band radiometric soil moisture retrieval. In 2004 IEEE Aerospace Conference Proceedings. 2004, (MT, USA), p. 1015-1023.

[8] NJOKU, E. G., WILSON, W. J. YUEH, S. H., et al. Observations of soil moisture using a passive and active low-frequency microwave airborne sensor during SGP99. IEEE Transactions on Geoscience and Remote Sensing, 2002, vol. 40, no. 12, p. 2659-2673. DOI: 10.1109/TGRS.2002.807008

[9] KERR, Y. H., WALDTEUFEL, P., WIGNERON, J.-P., et al. Soil moisture retrieval from space: The soil moisture and ocean salinity (SMOS) mission. IEEE Transactions on Geoscience and Remote Sensing, 2001, vol. 39, no. 8, p. 1729-1735. DOI: $10.1109 / 36.942551$

[10] ENTEKHABI, D., NJOKU, E. G., O’NEILL, P. E., et al. The soil moisture active passive (SMAP) mission. Proceedings of the IEEE, 2010, vol. 98, no. 5, p. 704-716. DOI: 10.1109/JPROC.2010.2043918

[11] KURUM, M., LANG, R. H., O’NEILL, P. E., et al. A first-order radiative transfer model for microwave radiometry of forest canopies at L-band. IEEE Transactions on Geoscience and Remote Sensing, 2011, vol. 49, no. 9, p. 3167-3179. DOI: 10.1109/TGRS.2010.2091139

[12] YUANYUAN JIA, ZHAOLIANG LI. Soil-vegetation-atmosphere radiative transfer model in microwave region. Chinese Geographical Science, 2008, vol. 18, no. 2, p. 171-177.

[13] SAATCHI, S. S., LE VINE, D. M., LANG, R. H. Microwave backscatter and emission model for grass canopies. IEEE Transactions on Geoscience and Remote Sensing, 1994, vol. 32, no. 1 , p. $177-186$. DOI: $10.1109 / 36.285200$

[14] CHAUHAN, N., LE VINE, D. M., LANG, R. H. Use of discrete scatter model to predict active and passive microwave sensor response to corn: Comparison of theory and data. IEEE Transactions on Geoscience and Remote Sensing, 1994, vol. 32, no. 2, p. 416-426. DOI: 10.1109/36.295056

[15] FERRAZZOLI, P., GUERRIERO, L. Passive microwave remote sensing of forests: A model investigation. IEEE Transactions on Geoscience and Remote Sensing, 1996, vol. 34, no. 2, p. 433-443. DOI: $10.1109 / 36.485121$
[16] KARAM, M. A. A physical model for microwave radiometry of vegetation. IEEE Transactions on Geoscience and Remote Sensing, 1997, vol. 35, no. 4, p. 1045-1058. DOI: $10.1109 / 36.602546$

[17] HORNBUCKLE, B. K., ENGLAND, A. W., DE ROO, R. D., et al. Vegetation canopy anisotropy at $1.4 \mathrm{GHz}$. IEEE Transactions on Geoscience and Remote Sensing, 2003, vol. 41, no. 10, p. 2211-2223. DOI: 10.1109/TGRS.2003.817192

[18] DOGUSGEN (ERBAS), C., HORNBUCKLE, B. K. A non-linear relationship between terrestrial microwave emission at $1.4 \mathrm{GHz}$ and soil moisture caused by ponding of water. Remote Sensing Letters, vol. 6, no. 3, p. 238-246. DOI: 10.1080/2150704X.2015.1029088

[19] FISCHMAN, M. A., ENGLAND, A. W. Sensitivity of a $1.4 \mathrm{GHz}$ direct-sampling digital radiometer. IEEE Transactions on Geoscience and Remote Sensing, 1999, vol. 37, no. 5, p. 2172-2180. DOI: $10.1109 / 36.789614$

[20] ANDERSON, M., NORMAN, J., MEYERS, T., et al. An analytical model for estimating canopy transpiration and carbon assimilation fluxes based on canopy light-use efficiency. Agricultural and Forest Meteorology, 2000, vol. 101, no. 4, p. 265-289. DOI: 10.1016/S0168-1923(99)00170-7

[21] ERBAS, C., HORNBUCKLE, B. K. Modeling diurnal changes in microwave emission from bare soil. In Proceedings of IEEE International Conference on Geoscience and Remote Sensing Symposium (IGARSS 2006). Denver (CO, USA), 2006, p. 1732-1735. DOI: $10.1109 /$ IGARSS.2006.448

[22] BURKE, W. J., SCHMUGGE, T., PARIS, J. F. Comparison of 2.8- and 21-cm microwave radiometer observations over soils with emission model calculations. Journal of Geophysical Research, 1979, vol. 84, no. C1, p. 287-294. DOI: 10.1029/JC084iC01p00287

[23] NJOKU, E. G., KONG, J. A. Theory for passive microwave remote sensing of near-surface soil moisture. Journal of Geophysical Research, 1977, vol. 82, no. 20, p. 3108-3118. DOI: 10.1029/JB082i020p03108

[24] COSTES, F., RAJU, S., CHANZY, A., et al. Microwave radiometry on bare soils: Comparison of various emission models of layered media with measurements. In Proceedings of IEEE International Conference on Geoscience and Remote Sensing Symposium (IGARSS 1994). Pasadena (CA, USA), 1994, vol. 3, p. 1579-1581. DOI: $10.1109 /$ IGARSS.1994.399503

[25] DOBSON, M. C., ULABY, F. T., HALliKAINEN, M. T., et al. Microwave dielectric behavior of wet soil. Part II: Dielectric mixing models. IEEE Transactions on Geoscience and Remote Sensing, 1985, vol. GE-23, no. 1, p. 35-46. DOI: 10.1109/TGRS.1985.289498

[26] CHOUDHURY, B. J., SCHMUGGE, T., CHANG, A., et al. Effect of surface roughness on the microwave emission from soils. Journal of Geophysical Research, 1979, vol. 84, no. NC9, p. 5699 to 5706. DOI: 10.1029/JC084iC09p05699

\section{About the Author...}

Cihan DOGUSGEN (ERBAS) was born in Istanbul, Turkey. She received her BS and MS degrees in Electronics and Communication Engineering from the Istanbul Technical University in 2001 and 2003, respectively. Then she was awarded her $\mathrm{PhD}$ degree in Electrical Engineering from Iowa State University, USA. She is currently an assistant professor of Electrical and Electronics Engineering at Istanbul Yeni Yuzyil University, Turkey. Her research interests include microwave radiometry, synthetic aperture radar data processing, and antenna design. 